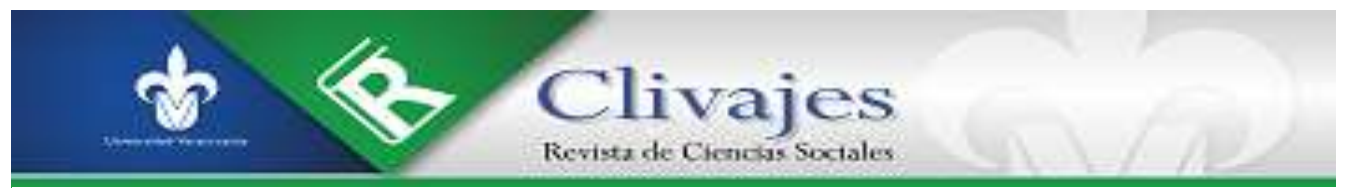

José Alfredo Zavaleta Betancourt

azavaleta@uv.mx

Instituto de Investigaciones Histórico-Sociales. Universidad Veracruzana

\title{
El LABERINTO DE OCTAVIO
}

DOI: https: / / doi.org/10.25009/clivajes-rcs.v0i14.2664

Clivajes. Revista de Ciencias Sociales. Año VII, número 14, julio-diciembre 2020, pp. 45-59.

https://clivajes.uv.mx/index.php/Clivajes/article/view/2664/4475

Instituto de Investigaciones Histórico-Sociales, Universidad Veracruzana

Clivajes. Revista de Ciencias Sociales/ISSN: 2395-9495/IIH-S, UV/Xalapa, Veracruz, México

Recibido: 25/09/2020

Aceptado: $15 / 10 / 2020$

Dictaminado: 17/12/2020

Clivajes. Revista de Ciencias Sociales (ISSN: 2395-9495), Año VII, Núm. 14, julio-diciembre, 2020

Instituto de Investigaciones Histórico-Sociales, Universidad Veracruzana, México 


\title{
EL LABERINTO DE OCTAVIO
}

\author{
José Alfredo Zavaleta Betancourt*
}

\begin{abstract}
Resumen
Este ensayo propone una interpretación de las posiciones políticas de Octavio Paz, con el propósito de identificar su legado político. Para tal efecto, a partir de la relectura de sus principales ensayos políticos, pone a discusión la idea de que nuestro poeta era un intelectual de izquierda socialista. En esta lógica, lo conceptúa como poeta con posiciones políticas, que discursivamente defendía un tipo de socialismo democrático desde una posición nacional-revolucionaria.

En la búsqueda de las reglas y estrategias discursivas utilizadas por Paz para hablar de la violencia, la izquierda, la democracia y el socialismo, en la incertidumbre, es posible identificar su crítica teórica desde el campo literario, con claras intervenciones en los campos político e intelectual. Octavio Paz deseaba, evidentemente, ilustrar a la izquierda mexicana con la advertencia de lo acontecido en los regímenes socialista-burocráticos. Su programa democrático, a mano para la izquierda de su tiempo y las actuales izquierdas, constituye una recuperación de la democracia liberal, un andamiaje para la sociedad mexicana, un proyecto de modernización no ensayado por el régimen priista y destruido, en su tiempo, por las burocracias socialistas del país.
\end{abstract}

Palabras clave: Crítica, Izquierda, Democracia, Violencia

\section{OCTAVIO'S LABYRINTH}

\section{Summary}

This essay proposes an interpretation of Octavio Paz's political positions, with the purpose of identifying his political legacy. For this purpose, the idea that Octavio Paz was an intellectual of the socialist left, based on the rereading of his main political essays, is put into discussion. In this logic, he is conceptualized as a poet with political positions, who discursively defended a type of democratic socialism from a national-revolutionary position.

In the search for the discursive rules and strategies used by Paz to talk about violence, the left, democracy and socialism, it is possible to identify his theoretical criticism from the literary field, with clear interventions in the political and intellectual fields. Octavio Paz, wanted, evidently, to enlighten the Mexican left with the warning of what happened in the socialist-bureaucratic regimes. Paz's democratic program, at hand for the left of his time and the current left, constitutes a recovery of liberal democracy, a scaffolding for Mexican society, a modernization project not tested by the PRI regime and destroyed, in its time, by the socialist bureaucracies of the country.

Keywords: Criticism, Left, Democracy, Violence

\section{LE LABYRINTHE D’OCTAVIO}

\section{Résumée}

Cet essai propose une interprétation des positions politiques d'Octavio Paz, afin d'identifier son héritage politique. Pour ce faire, on met en discussion l'idée qu'Octavio Paz était un intellectuel de gauche socialiste, à partir de la relecture se ses principaux essais politiques. Dans cette logique, on se fait une conception de lui comme un poète d'idées et postures politiques qui défendait discursivement un type de socialisme démocratique à partir d'une position nationale-révolutionnaire.

\footnotetext{
* Doctor en Sociología, Investigador de Tiempo Completo con Perfil PRODEP. Integrante del cuerpo académico "Estudios sociopolíticos" (IIH-S, UV); miembro del Sistema Nacional de Investigadores, Nivel II, y de la Academia Mexicana de las Ciencias, Área de Ciencias Sociales. Premio al Decano 2018 de la Universidad Veracruzana, México. Línea de Investigación: Sociología de la Violencia. Contacto: azavaleta@uv.mx.
} 
Dans la recherche des règles et stratégies discursives utilisées par Paz pour parler de la violence, la gauche, la démocratie et le socialisme, il est possible d'identifier sa critique théorique à partir du champ littéraire, avec des claires interventions dans les champs politiques et intellectuels. Octavio Paz désirait évidement, illustrer la gauche mexicaine avec l'avertissement ce qui est arrivé dans les régimes socio-bureaucratiques. Le programme démocratique de Paz, de la main de la gauche de son époque et des gauches actuelles, constitue une récupération de la démocratie libérale, une structure pour la société mexicaine, un projet de modernisation pas essayé par le régime du PRI, et détruit dans son époque par les bureaucraties socialistes du pays.

Mots clés : Critique, Gauche, Démocratie, Violence

\section{INTRODUCCIÓN}

En las celebraciones del centenario de su nacimiento (2014), para sorpresa de muchos, algunos herederos del poeta y ensayista describieron la trayectoria intelectual y política de Octavio Paz (1914-1998), como una posición de izquierda y socialista en el campo político. ¿Qué defendía Octavio Paz?, ¿qué métodos utilizaba para debatir con sus adversarios?, ¿qué utilidad tienen sus posiciones intelectuales y políticas para el debate público en la actualidad? Para responder a estas preguntas, es posible emprender una descripción de la intervención del poeta en el campo político e intelectual de su generación, a partir de las estrategias discursivas utilizadas por los participantes, incluida la búsqueda de su consagración literaria.

En este ensayo se sostiene que Octavio Paz defendió discursivamente un tipo de socialismo democrático, con un posicionamiento nacional-revolucionario, mediante una observación que lejos estaba de proponer un modelo de sociedad alternativo al capitalismo. A lo sumo, "hijo de la crítica", aceptaba el mercado al que creía necesario, pero injusto, y a la democracia, de la cual no esperaba ni la virtud ni la felicidad. Desde ese emplazamiento, sostuvo la necesidad de no repetir los errores del socialismo burocrático, una agenda de propuestas democráticas, y eso representa su legado principal para la izquierda latinoamericana.

\section{LA CRÍTICA SEGÚN PAZ}

Para perplejidad de muchos lectores, Enrique Krauze (2011) presentó a Paz como un intelectual de izquierda y socialista. ${ }^{1}$ Esta propuesta de lectura de las posturas políticas

\footnotetext{
${ }^{1}$ Krauze (2014) sostiene que "Paz escribe para los lectores de izquierda. Son los únicos que le importan y, hasta cierto punto, son los únicos que existen (...) Paz, es verdad, se había vuelto reformista. Pero no era liberal, sino un peculiar socialista libertario" (pp. 178, 181). 
del poeta contrasta con la idea de quienes sostienen que éste ya no era socialista en los noventa (Domínguez Michel, 2014; Nettel; 2014; Vargas Llosa, en Santi, 2009, p. $517)^{2}$ y también con las últimas posiciones políticas de Paz en torno al salinismo y la rebelión neozapatista.

El análisis de tales posiciones es útil no sólo para la deconstrucción de los usos singulares de la obra del Premio Nobel (1990) o de su imagen como "caudillo cultural”, sino porque en ellas hay elementos que no observamos o no entendimos en su contexto, cuando en algún momento calificamos de impostura sus discursos sobre las revoluciones centroamericanas y su crítica al socialismo cubano. Para nosotros, en los ochenta, Paz era un intelectual de derecha, utilizado por los regímenes imperialistas para debilitar a la hegemonía socialista, tocado por la simpatía de haber intercambiado una carta con el trostkista argentino Adolfo Gilly, encarcelado en México. ${ }^{3}$

Ahora, después de la implosión del socialismo burocrático y de la transición política en México, reconocemos que Paz "veía más” que algunos intelectuales progresistas cercanos a la izquierda mexicana, pero no sin las contradicciones de un intelectual nacional-revolucionario poco tolerante a la crítica, y del cual, en retrospectiva, no estamos seguros "de si su influencia es del todo positiva", tal como dice Villoro, quien incluso, añade: "fue una figura impositiva (...) no quería colaboradores, sino discípulos, gente que comulgara con sus obsesiones y las propagara (...) tampoco le gustaba que ese privilegio se usara para discrepar con él” (Villoro \& Stavans, 2014, pp. 64-69).

Para aproximarnos a las ideas de Paz, la lectura propuesta se limita a los escritos donde diserta sobre la violencia, la izquierda, la democracia y el socialismo. En esta tarea, son importantes, entre otras fuentes, sus ensayos políticos. La tarea puede calificarse de parcial, porque hay quienes piensan que es incorrecta la separación de su

\footnotetext{
${ }^{2}$ Para evidencia de las distintas clasificaciones, puede considerarse que "el pensamiento de Paz estuvo mucho más cerca del socialismo democrático de nuestros días que del conservadurismo e, incluso, que de la doctrina liberal. De las simpatías trotskistas y anarquistas de su juventud marcada por el surrealismo evolucionó luego hasta la defensa de la democracia política, es decir, del pluralismo y el estado de derecho” (Vargas Llosa en Santi, 2009, p. 517); o bien: “¿Murió Paz siendo el gran intelectual de derecha en México, como lo calificó el subcomandante Marcos? ¿Terminó por ser un liberal, un neoliberal o un neoconservador, inclusive, quien había comenzado siendo de izquierda? (...) Paz sueña con que, en el futuro, socialismo y liberalismo puedan ser sintetizados (...) En los años noventa, por primera vez puede decirse que Paz ya no pertenece a ninguna de las viejas familias socialistas y los liberales más puros u ortodoxos están dispuestos a recibirlo en su seno sólo como un viejo compañero de viaje" (Domínguez Michael, 2014, pp. 543-546).

${ }^{3}$ La amistad intelectual de Paz y Gilly se manifiesta en la lectura que el segundo hace de las intervenciones del primero acerca de la rebelión neozapatista. Al respecto, resulta útil considerar que: "un viejo hombre de izquierda como Gilly (...) recuerda cuando los jóvenes le dicen que Paz estuvo en 1994 contra Marcos y los neozapatistas, él responde: Bueno, aquí están los textos. Nos vemos en una semana. Transcurrido el plazo y leídos aquellos textos, dice Gilly, no es evidente para esos mismos jóvenes que Paz estuviera en contra de los zapatistas” en 1994 (Domínguez Michael, 2014, p. 505).
} 
obra ensayística con respecto a su obra poética, y hay quienes consideran imprescindible analizar en dicha obra la tensión permanente entre las posiciones estéticas y políticas del autor. En este caso, para aislar selectivamente sus posturas políticas, nos adherimos a lo que Paz defendía en cuanto a la autonomía del campo literario. Para tal efecto, la estratégica publicación por temas de sus Obras Completas, si bien facilita la elección de textos, complica el reconocimiento del orden cronológico de sus ideas.

En estas circunstancias, una descripción de las posiciones políticas de Paz, mediante el criterio de discontinuidad, puede ayudarnos a comprender qué reglas posibilitaban sus discursos de índole política. ${ }^{4}$ Los textos políticos de Paz son cultos y se caracterizan por un estilo de catecismo; en éstos, las obsesiones políticas del autor son circulares, ${ }^{5}$ representan "un recomienzo" o, en sus propias palabras, quizás una recaída: "el comienzo de algo que todavía no termina, una búsqueda circular y que ha sido un perpetuo recomienzo" (Paz, 2001, p. 7). De ahí que la lectura de sus ensayos políticos sea y enfrente, a veces, la constatación de que nuestro autor repite una y otra vez, con mordacidad, las fórmulas o etiquetas, las clasificaciones y descalificaciones, los datos fragmentarios.

El estilo de Paz, ${ }^{7}$ al igual que el de Borges, resulta mágico, impresiona: la lectura de sus ensayos políticos fabrica la ilusión de que ha leído todos los libros, así sea por el carácter fictivo de algunos de sus enunciados. Afirma Villoro que Paz escribía a "contrapelo"; defendía la autonomía de la literatura respecto de todo régimen político; sabía perfectamente que haber trabajado para el Estado mexicano, como diplomático,

\footnotetext{
${ }^{4}$ Con respecto a la relación de Paz con Foucault, un indicio: “A Octavio Paz - dice Jorge Castañeda- lo he visto una vez en mi vida; estuve con él 15 minutos, por un encargo de Michel Foucault hace 15 años” (Toledo \& Jiménez, 1994, p. 195).

5 "Paz vivió y murió obsesionado por la aurora que se convirtió en pira sangrienta, el comunismo del siglo XX: primero como ortodoxo, luego como heterodoxo” (Domínguez Michael, 2014, p. 19).

6 "Al revisar estos sesenta años me doy cuenta de que esta peregrinación me ha llevado a mi comienzo. Ante el panorama contemporáneo siento la misma insatisfacción que experimenté en mi juventud, ante el mundo moderno. Creo, como antes, que debemos cambiarlo, aunque yo ya no tenga fuerzas ni edad para intentarlo. Tampoco sé cómo podría hacerlo. Nadie sabe. Los antiguos métodos fueron no sólo ineficaces sino abominables (...) yo no rechazo la solución socialista. Al contrario, el socialismo es, quizá, la única salida racional a la crisis de occidente. Pero, por una parte, me niego a confundir al socialismo con las ideocracias que gobiernan en su nombre (...) por otra parte pienso que el socialismo verdadero es inseparable de las libertades individuales, del pluralismo democrático y del respeto de las minorías y los disidentes” (Paz, 2001, p. 61).

${ }^{7}$ Al respecto, señala Aguilar Mora (1978): "El estilo de Paz es híbrido en sus mecanismos: recoge todas las ideas de la crítica irónica, pero guarda el signo de la disidencia, de la transformación de la filosofía marxista, de la nietzscheana y del proyecto de revolución permanente de Trostky" (p. 110).
} 
lo hacía un dominado, con respecto al ogro filantrópico, y estaba consciente de su relación de intercambio con los medios de comunicación ${ }^{8}$.

En el campo intelectual, Paz desarrolló un tipo de crítica heredera de la crítica europea del capitalismo. Decía que su ejercicio de la crítica se hacía desde la tradición de izquierda: "soy hijo de los grandes críticos del racionalismo: Freud, Nietzsche..." (Paz, 1993, p. 163). Quizá podamos inferir que a estos últimos puntos suspensivos seguía, reprimido, el nombre de Marx, de quien Paz pensaba que había desarrollado una idea simple de la historia y la sociedad, pero no era responsable del socialismo burocrático, aunque para nuestro poeta, a pesar de su vitalidad crítica, el marxismo no era una ciencia, sino una "hipótesis equivocada".

Así, Paz abandonó la crítica trostkista del socialismo real, mediante la crítica democrática, que incluyó el rechazo del propio Trostky. En su desencanto político, fue definitivo el colapso del socialismo burocrático. Paz habló ininterrumpidamente durante tres décadas de "una peste totalitaria", de los "métodos abominables", de la "abyección" de la "perversa parodia de la comunión religiosa". La caída del muro "de cemento, piedras, sangre" fue la prueba, la evidencia, la señal que esperaba. "Los crímenes del régimen burocrático son suyos y bien suyos, no del socialismo”, afirmaba (Paz, 1979, p. 238).

Durante muchos años, Octavio Paz defendió posiciones en debates eurocéntricos; por ejemplo, se alineó a Camus contra Sartre, a propósito de la polémica de ambos acerca de la violencia. No sabremos nunca si en verdad Paz advirtió a Camus sobre el inevitable ataque en Los tiempos modernos a El hombre rebelde; sin embargo, esa anécdota, narrada por Paz, evidencia que tomó distancia de Sartre por motivos literarios - aquél no valoraba como él la literatura-y políticos, sobre todo políticos, pues le reprochaba haber guardado silencio acerca de los crímenes estalinistas.

En general, las ideas de Paz con respecto a la violencia son similares a las de Camus. Nuestro poeta comparte con el argelino -a quien describía como "buen amigo", pero inexplicablemente, como el mismo Sartre, lo trataba como "pensador de segunda mano"- el rechazo a la violencia, lo cual puede documentarse en los artículos de Camus compilados en Ni víctimas ni verdugos (2014). Al respecto, a diferencia de

\footnotetext{
8 “No estoy cerca del poder ni de Televisa. He usado a Televisa como Televisa me ha usado a mí de la misma manera en que todo mundo usa un medio de comunicación. También he colaborado en La Jornada y nadie dice que soy agente de ese periódico" (Paz, en Domínguez Michael, 2014, p. 394).

9 "Mis afinidades intelectuales y morales, mi vida misma e incluso mis críticas, son parte de la tradición de la izquierda” (Paz, 2001, p. 261).
} 
Sartre - de quien Paz opinaba que era mejor su literatura que su filosofía-, el cual defendía el uso de la violencia descolonizadora, Camus pensaba que, aun cuando la violencia era inevitable, no debía legitimarse políticamente, porque "las palabras son más fuertes que las balas". ${ }^{10}$

Las invectivas de Paz contra Sartre, como "deslenguado" y “contradictorio”, sus notas acerca del desconocimiento sartreano del teatro español del siglo XVI y la bizarra imagen que forjó del filósofo, a quien "auxilió desde el consulado francés para viajar a México" y al que dejó sólo en su apartamento cuando éste cantaba "Vámonos”, de José Alfredo Jiménez - si acaso es cierta la anécdota reproducida por Savater- no dejan de ser malévolas y denotan una mala relación. ${ }^{11}$

Es evidente que las ideas de Paz acerca del socialismo y la democracia no eran descripciones metódicas de estos regímenes, sino pastiches contra el socialismo burocrático; sin embargo, en la "ultrageneralización", en el "uso de generalizaciones y anfibologías", como señalaba González Rojo (1989), ${ }^{12}$ advertía a la izquierda latinoamericana acerca de la complejidad que implicaba la construcción de una sociedad socialista, justa y democrática, acerca de un nuevo proyecto que sintetizara el socialismo y el liberalismo.

Paz, como veremos adelante, describía a la izquierda como secta; al socialismo como la salida racional a nuestros problemas y a la democracia como una forma de convivencia. La izquierda era para él poco reflexiva y "tenía que recuperar su herencia crítica legítima”; el socialismo - tal como aprendió de Víctor Serge-debía respetar las

\footnotetext{
10 "No pienso que haya que responder a los golpes con una bendición. Creo que la violencia es inevitable (...) no diré que hay que suprimir todo tipo de violencia (...) sólo digo que hay que rechazar cualquier tipo de legitimación (...) Es a la vez necesaria e injustificable (...) No predico pues la no violencia, por desgracia, sé que es imposible, ni como dicen los bromistas, la santidad (...) Me horroriza la violencia cómoda. Es un poco fácil matar en nombre de la ley o de la doctrina” (Camus, en Marin, 2014, pp. 71-72).

11 "En la crisis del París de la postguerra que hemos evocado, Octavio Paz, según lo recordó él mismo, cayó del lado de Camus en contra de Sartre, de Rousset en contra de Aragón (...) del lado de la inquietud contra el dogmatismo, de la verdad contra el mito, de la cara contra la máscara” (Lafaye, 2013, p. 105).

“(...) agudiza su crítica al estalinismo y los autoritarismos en general. Los diálogos con el mismo Péret, con Victor Serge y Jean Malaquais le aportan argumentos que consolidan sus opiniones sobre estos sistemas políticos y las opresiones que acarrean (...) desde principios de izquierda e incluso de ideas libertarias (...) Paz debate sin éxito con Sartre” (Ollé-Laprune y Bradu, 2014, pp. 9, 10).

“A Paz, en su ensayo de 1980 escrito al morir el autor de La náusea, le desagradó que, en el último de sus tres o cuatro encuentros con Sartre en el medio siglo, éste le hablase de oídas de Santa Teresa, sin haberla leído, cómo era capaz de decir que El diablo y el buen Dios, se inspiraba en El Rufián dichoso de Cervantes, que tampoco había leído (...) Paz finalmente, también ayudó a Sartre en el consulado, cuando viajó de incógnito con Dolores Vanetti, una de sus amigas, a México en el verano de 1949” (Domínguez Michael, 2014, p. 152).

12 "Se mueve, por lo visto, como pez en el agua en el mundo de las vaguedades y las anfibologías (...) amalgama un puñado de tesis, puntos de vista (...) La definición de la forma de gobierno de la Unión Soviética como despotismo totalitario es pobre y redundante" (González Rojo, 1989, p. 34).
} 
libertades democráticas, y la democracia, instituirse como hábito o "segunda naturaleza" basada en el diálogo.

Las ideas del poeta acerca de la izquierda socialista pueden describirse con la metáfora de la ceguera de una corriente política. Evidentemente, para quienes recordamos su apoyo inicial al proyecto de modernización salinista, la crítica del uso neozapatista de la violencia, sus "temores" y “deseos" de que el priismo triunfara en las elecciones de 2004, y los cuidados que el Ejército le brindó durante sus últimos días ${ }^{13}$ es inverosímil el relato del socialista libertario que hablaba desde posiciones de izquierda; no obstante, podemos ponderar en su justa dimensión sus contribuciones a la caracterización de las burocracias socialistas, a la crítica de las dictaduras latinoamericanas y a la oferta democrática en nuestro país, como la realizada por José Revueltas.

\section{LA IZQUIERDA, EL SOCIALISMO Y LA DEMOCRACIA EN PAZ}

Entre los lectores de Paz se ha hecho lugar común la idea de que no tenía "interlocutores de su medida", pero, como hemos dicho, el ensayista, que practicaba la crítica radical, no quería interlocutores, sino adversarios. La idea “pacifista” del diálogo propugnada por él resulta muy particular: no implica la supresión del conflicto ni la inexistencia de adversarios. Sí, por supuesto, se oponía a la eliminación ideológica o física de los enemigos. Paz habló "desde la izquierda", se autodescribía de izquierda, pero ¿desde cuál izquierda hablaba? Defendía el socialismo, pero ¿qué socialismo defendía? Proclamaba la democracia, pero ¿cuál democracia refería?

Para responder a estas preguntas no tiene mucho sentido reproducir la hipótesis del "desencanto paulatino y creciente" o la "evolución incompleta o malograda al liberalismo" como la ruptura con su pasado marxista, al que describiría como una superstición pseudorreligiosa. ${ }^{14}$ Al respecto, el mismo Paz (2001) señalaba: “¿La derrota del comunismo significa la victoria del capitalismo? Sí, a condición de añadir que no ha sido la victoria de la justicia ni de la solidaridad entre los hombres" (p. 49).

\footnotetext{
13 “Murió como un jefe de Estado" (Villoro y Stavans, 2014, p. 65). Asimismo: “causó inquietud y disgusto, incluso entre los hombres que no eran de izquierda y conocían muy bien lo ajeno que es el ejército mexicano al aristocratismo elitista y golpista del resto de los militares latinoamericanos, que Paz muriera no sólo bajo el cuidado paternal del presidente de la República, sino custodiado por soldados y atendido por médicos militares” (Domínguez Michael, 2014, pp. 566, 567).

14 "En 1951 había denunciado los campos de concentración en ese país. Su desencanto había sido paulatino y creciente, pero sus textos posteriores sobre el tema, aunque críticos, se habían movido siempre en el nivel de las opiniones más que del análisis documentado" (Krauze, 2014, p. 192).
} 
Inicialmente, la actitud crítica de Octavio Paz era libertaria, heredera del anarquismo, del marxismo clásico y del trotskismo; después, juzgó de forma asimétrica al capitalismo y al socialismo burocrático y defendió una idea genérica de la democracia. Tenía razón: era necesario evitar los errores del socialismo real, pero, mediante la observación evolucionista de la historia universal, infería, mecánicamente, que la izquierda, incluido el neozapatismo, conduciría inexorablemente a la misma tragedia del socialismo y de las dictaduras militares. En 1994, fustigaba: “¿Esto es lo que quieren para México?” (Paz, 2000).

A menudo, el poeta explicaba las razones personales por las cuales no hacía una crítica enfática a la democracia estadounidense o a las democracias europeas; no obstante, sin dejar de hacerlo, rechazaba el reproche, injusto por cierto, sobre la elisión de la crítica a las dictaduras militares sudamericanas. En la coyuntura del colapso del socialismo real, Paz consolidó el polo democrático contra la izquierda; abogó en el campo intelectual, hasta los años sesenta, por un socialismo democrático, ${ }^{15}$ pero no advirtió que la democracia sería distorsionada por los medios de comunicación ni que la modernización salinista en nuestro país no significaba la superación del patrimonialismo. En eso, el crítico radical fue un nacional-revolucionario; hijo de la Guerra Fría, no observó sistemáticamente, no tuvo tiempo, la transición del capitalismo tardío al capitalismo postmoderno, ni de la democracia imperial al imperio de la soberanía de las multinacionales.

\section{El LEGAdo POlítico de PaZ}

Aunque Octavio Paz prefería hablar de memorial, que de un legado, preguntemos: ¿cuál es el legado político de Paz? o “¿qué programa nos ha legado?” Son interrogantes que algunos hicieron en el homenaje final al poeta en el Palacio de Bellas Artes (Monsiváis, 2000, p. 104). Para responder, no deseamos cuestionarnos: “¿Por qué Octavio Paz no encontró a los interlocutores que merecía dentro de la izquierda mexicana?” (Krauze, 2011), o bien, “¿qué fue lo que impidió que Paz se ahogase en el diluvio de los años treinta? ¿Por qué no se convirtió en uno de los militantes abnegados o de los poetas deshonrados?” (Domínguez Michel, 2014, p. 55).

Poco ayudan tales preguntas a la comprensión de los “encuentros y desencuentros” del poeta con la izquierda mexicana o a la comprensión de en qué

\footnotetext{
15 "Paz nunca estuvo a la vez tan cerca y tan lejos de la izquierda militante como en los años sesenta” (Domínguez Michael, 2014, p. 378).
}

Clivajes. Revista de Ciencias Sociales (ISSN: 2395-9495), Año VII, Núm. 14, julio-diciembre, 2020 Instituto de Investigaciones Histórico-Sociales, Universidad Veracruzana, México 
específicamente benefició a la izquierda de su tiempo, antes de sostener, como hace Roger Bartra, que ésta fue la única beneficiaria. Por supuesto, la respuesta debe construirse fuera del círculo de adeptos o de la red de "hijos o nietos", "cada uno huérfano a su manera", como apunta Christopher Domínguez (2015), es decir, al margen de la estrategia de consagración y la disputa central por la herencia legítima de sus discípulos. La descripción de los enunciados de Paz sobre la izquierda nos ayuda a comprender la ruptura discursiva entre las convicciones radicales, antifascistas, de su juventud y la crítica profética al estalinismo y al socialismo burocrático de su madurez. De acuerdo con Domínguez Michel (2007):

Paz se alejó del marxismo tras un proceso que él ha descrito puntillosamente. En 1950, al denunciar los campos de concentración soviéticos, el poeta se alejó tajantemente del estalinismo. Más tarde, renunció a la idea de que éste era una patología pavorosa, pero patología al fin, en el cuerpo presumiblemente sano del comunismo de Marx, Lenin, Trotsky. Este segundo movimiento, que no podía llevar sino al reencuentro con la tradición liberal (p. 481).

En efecto, Paz se autodescribía como poeta y ensayista, y hablaba desde el campo literario, desde un emplazamiento diplomático, inicialmente político y luego editorial. ${ }^{16}$ La mayor parte de sus discursos retrospectivos acerca de su trayectoria intelectual se producen con una estrategia de enunciación, que ficciona la autonomía absoluta del escritor respecto de las instituciones estatales, y la estrategia eurocéntrica de la vanguardia - de quien observa a los latinoamericanos mediante conceptos y teorías europeos-, según la cual: "la verdadera enfermedad de América Latina no es por tanto, la herencia colonial sino el retraso de la reflexión política económica y social" (Paz, en Sortman, 1989, p. 206). En tales circunstancias, nuestro poeta subrayó la crítica al estalinismo y la burocracia socialista como régimen autoritario que asesinaba a su población, particularmente a los escritores: "El estado burocrático totalitario ha perseguido, castigado, asesinado a los escritores, los poetas y los artistas con un rigor y una saña que habría escandalizado a los mismos inquisidores" (Paz, 1979, p. 8).

\footnotetext{
16 "La infiltración de lo político en el seno de la crítica literaria no pasó inadvertida en Vuelta y, de hecho, se convirtió en una más de las razones para adjurar de la academia. Aunque Paz tuvo un gran interés en la obra de Jacobson, las tendencias políticas de quienes más tarde continuarían las ideas del lingüista, enturbiaron definitivamente el interés de Vuelta en ellos. Esto se hace claro al leer un apunte sobre Foucault, aparecido en el número 98 (...) con motivo del fallecimiento del francés (...) Ruy Sánchez hace énfasis en las que llama bodas lógicas del estructuralismo con el marxismo ocurridas a partir de la aparición del libro de Althusser Pour Marx y el colectivo titulado Para Leer el Capital. Independientemente de que la obra de Foucault se alejaba de la aventura althusseriana, esa acotación es significativa de las razones por las que en Vuelta los teóricos eran vistos con algo más que reserva” (Flores, 2011, pp. 139, 140).
} 
Octavio Paz no fue historiador ni arqueólogo ni sociólogo, fue un poeta y ensayista con posiciones políticas, a quien el desencanto lo llevó a diferenciar entre campos literarios y políticos. ${ }^{17}$ Sus citas sobre la sociología de su tiempo estaban equivocadas y acaso ocultaban la causa de su desdén por la investigación empírica, ligadas quizá a la confesión de haber decidido no escribir novelas por falta de tiempo; sin embargo, en una de sus reiteraciones sostiene: "nuestros sociólogos deberían leer o releer a Macbeth, Otelo, Hamlet. Y lo que digo de Shakespeare puede extenderse a Balzac, Stendhal, Tolstoi, Galdós. Y claro está, a los poetas, a Dante y a Milton, a Quevedo y a Machado" (Paz, 1993, p. 497).

Paz registró la ruptura con sus creencias “comunistas" en los años sesenta y la describió como una "desintoxicación” o "cura” desde la izquierda. ¿Fue Octavio Paz un revolucionario o un nacionalista-revolucionario? La respuesta a esta pregunta puede indicarnos que, cuando abdicó a la violencia, rechazó la revolución -a la que alguna vez pensó como "un proyecto generoso" -y el socialismo burocrático. ${ }^{18} \mathrm{Al}$ respecto, Krauze (2014) afirma que: “José Luis Martínez se atrevió a decir en voz baja: “Octavio, tú en realidad nunca fuiste un revolucionario”. Paz se levantó de su asiento y reclamó en voz alta, casi con ira: “¿Qué dices? ¿Qué yo no fui revolucionario? Martínez (...) se refería a la acción revolucionaria (...) Paz, por su parte, había practicado la Revolución a través de la poesía y del pensamiento” (p. 266). La anécdota localiza a Paz en el campo literario y lo diferencia de la posición militante de José Revueltas. En efecto, nuestro poeta fue experimental en el campo literario; radical en su juventud, pero socialdemócrata en política durante su madurez. Quizá Bartra (2013) tenga razón: discursivamente, Paz era, al mismo tiempo, reformista y revolucionario, porque "el culto a la revolución dejó cicatrices en (su) pensamiento”.

Tal vez, se comprenda mejor a Octavio Paz como un intelectual nacionalrevolucionario, pues su trayectoria política resulta inexplicable sin la cultura del régimen priista, precisamente nacional-revolucionario, al que consideró menos nocivo

\footnotetext{
${ }^{17}$ Decía: "En cuanto a la sociología: su materia y sus límites son vagos, sus conclusiones inciertas" (Paz, 2011, p. 146). Asimismo: "Pero no es necesario seguir a Marx para darse cuenta que los sociólogos, cuando lo son de verdad, son historiadores que se ignoran. La sociología dice Paul Veyne, es una fraseología o una descripción, no una explicación” (Paz, 2010, p. 92). Es útil también: "Mi maestro me dijo que estaría bien que me aprovechara de la presencia de Octavio Paz en París para entrevistarme con él, que aunque no fuera historiador, antropólogo, ni arqueólogo, sino poeta, sí entendía mucho del pasado mexicano" (Lafaye, 2013, p. 18).

18 "La idea revolucionaria fue y es un proyecto muy generoso. Mis afinidades intelectuales y morales, mi vida misma e incluso mis críticas, son parte de la tradición de la izquierda” (Paz, 2001, p. 261).
} 
que el estalinismo, ${ }^{19}$ no obstante que llegó a ver con buenos ojos lo simbólico de la candidatura de Rosario Ibarra a la presidencia, como un signo del porvenir político mexicano. ${ }^{20}$ En diferentes entrevistas y ensayos, Paz declaró que algunos escritores antiestalinistas habían sido decisivos para su "cura"; por ejemplo, Serge, Rousset, Camus, Solzhenitsyn y Papaioannou; en efecto, sus diálogos con estos escritores fueron posibles gracias a acontecimientos discursivos en torno a las críticas a Gide en Valencia, las revelaciones de Rousset, la recepción de Solzhenitsyn en París y el caso del escritor cubano Heberto Padilla.

Paz siempre rechazó los adjetivos que sus críticos asociaban a su nombre: "conservador", "neoliberal", "anticomunista", y tenía razón, pero no militó ni se alistó en el frente de la Guerra Civil Española, y sus posiciones de madurez no fueron tan incisivas con el viejo régimen político priista. En el campo intelectual, a Octavio Paz le interesaba, sobre todo, el reconocimiento de su primacía en haber dicho algo en México: ${ }^{21}$ la denuncia de los campos de trabajo forzado, la vindicación de la democracia, la necesidad de un proyecto político-social diferente a los ensayados hasta antes de su muerte.

La polémica con Monsiváis muestra a Paz en su justa dimensión. El intercambio de ideas y ficciones de estos dos escritores, que desde una revista del centro del país hablaban en nombre de posiciones políticas unitarias, pone en evidencia la estrategia discursiva con la cual Octavio Paz -paradójicamente, puesto que rechazaba el estilo de Sartre- trataba a Monsiváis, la misma que Sartre utilizó contra Camus, al considerarlo no-filósofo.

En esta polémica, las estrategias son encomiables: Monsiváis se queja de la pontificación y la hipóstasis, mientras que Paz lo hace de la confusión de ideas y falta de argumentos. Al respecto, Christopher Domínguez (2014) afirma: "A la distancia se advierte que Paz utilizó a Monsiváis para remachar su ruptura con la izquierda y que el cronista, al desafiarlo, le sirvió para concluir con su proceso de reinserción en México, primero en la izquierda y luego contra ella, al fracasar su participación en su imposible reforma" (p. 399).

\footnotetext{
19 "Hay un anquilosamiento intelectual de la izquierda mexicana, prisionera de fórmulas simplistas y de una ideología autoritaria no menos, sino más nefasta que el burocratismo del PRI y el presidencialismo tradicional de México" (Paz, en Monsiváis, 2014, p. 87).

20 “En 1982 vio con beneplácito la candidatura, presentada por los trotskistas, a la presidencia de la República de Rosario Ibarra de Piedra, a quien la desaparición forzada de su hijo, durante los operativos antiguerrilleros de los años setenta, había llevado a la política" (Domínguez Michael, 2014, p. 388).

21 "Yo soy el primer escritor que se enfrentó al estalinismo (...) ¿Y José Revueltas? pregunta el periodista (...) ¡Nunca antes que yo! ¡Yo fui el primero!” (Paz, en Ponce, 2014, p. 45).
} 
Por otra parte, a pesar de que aseguraba que no había buscado el Nobel, aunque lo deseara, la estrategia discursiva de Paz lo condujo a alcanzar el Premio, mediante un bajo tono en sus críticas a la democracia liberal y otro, por demás elevado, contra los crímenes y asesinatos del socialismo real. Podría decirse - es una conjetura- que si el Nobel a Camilo José Cela fue “para la España de Felipe” (Paz, en Ponce, 2014, p. 44), el de Octavio Paz fue para la apertura comercial y la reforma estatal de Salinas de Gortari.

En el campo político, Paz intervino siempre como el crítico que recordaba que los europeos no conocían a los latinoamericanos, y a los latinoamericanos reprochaba que desconocían a los europeos; sin embargo, el análisis de los enunciados de Paz sobre Nietzsche, Freud y Marx revela que su conocimiento acerca de éstos no era sistemático, como sucedía también respecto de otros filósofos franceses; ejemplo de ello es la clasificación de Foucault como comentarista de Heiddegger. En sus palabras (2003): "En cuanto a la fenomenología y sus herederos no hay nadie después de Sartre. Sus sucesores son comentaristas de Heidegger, como Foucault y Derrida” (p. 521).

Octavio Paz defendía la idea del intelectual autónomo del Estado, pero no advirtió que los medios de comunicación que utilizaba se convertirían en un mecanismo de control político en el capitalismo actual. El legado del "último intelectual mexicano" (Loaeza, 1998) no son la idea de un nuevo partido político ni una nueva ideología, aunque su microprograma: integración de un poder legislativo independiente, creación de un poder judicial fuerte, separación de todo partido político respecto del Estado, renuncia presidencial al nombramiento de sucesores y un nuevo federalismo (Paz, 2001, p. 302), sigue siendo imprescindible y está pendiente en México, sino una actitud crítica que nos recuerda que "la revolución era hija de la crítica y que la ausencia de la crítica había matado a la revolución”. Desde la perspectiva de Paz (1979):

La izquierda latinoamericana lucha contra formidables enemigos: el imperialismo norteamericano - hoy más o menos tranquilo en sus flancos internacionales gracias a su doble entendimiento con Rusia y China-, las grandes oligarquías, la casta militar y los restos de los antiguos partidos conservadores. La tarea más urgente de los movimientos realmente democráticos y socialistas de la América latina es elaborar programas viables y diseñar una nueva estrategia y una nueva táctica (p. 272).

Esta es, ni más ni menos, la agenda que la izquierda tiene a la mano para forjar una sociedad más justa y libre, para dejar atrás el ciclo de la barbarie capitalista y socialista, y para encauzar la institucionalización de una sociedad socialista democrática; 
en suma, lo que el propio Octavio Paz, ya glorificado como el pensador más célebre de América Latina durante el siglo Xx, presentaba como opiniones de buena fe, a la espera de que "la durmiente (...) despertara del bosque", tal como se refería a la izquierda mexicana de los años setenta. Es hora, entonces, de que también sus herederos legítimos asuman este legado político, en lugar de imitar inútilmente la enunciación señorial de nuestro poeta.

\section{REFERENCIAS}

Aguilar Mora, J. (1978). La divina pareja. Historia y mito en Octavio Paz. México: Era.

Bartra, R. (2013). Conversaciones frenadas. Letras Libres. Recuperado de https://n9.cl/btrsm.

Camus, A. (2014). Ni víctimas ni verdugos. Buenos Aires: Ediciones Godot.

Camus, A. (1978). Moral y política. Buenos Aires: Alianza-Losada.

Domínguez Michael, C. (2014). Octavio Paz en su siglo. México: Aguilar.

Domínguez Michael, C. (2007). Diccionario crítico de la literatura mexicana, 1955-2011. México: FCE.

Flores, M. (2011). Viajes de Vuelta. México: FCE.

González Rojo, E. (1989). El rey va desnudo. Los ensayos políticos de Octavio Paz. México: Posada.

Krauze, E. (2014). Octavio Paz. El poeta y la Revolución. México: Penguin Random House.

Krauze, E. (2011. octubre). La herejía de Octavio Paz. Revista Vuelta, 13.

LAfaye, J. (2013). Octavio Paz en la deriva de la modernidad. México: FCE.

LoAeza, G. (1998). Octavio Paz: El último intelectual mexicano. Nexos. Recuperado de: https://n9.cl/ruy2s.

Marin, L. (2014). Albert Camus. Escritos libertarios. México: Tusquets.

Monsiváis, C. (2000). A donde yo soy tú somos nosotros. México: Hoja Casa Editorial.

NetTel, G. (2014). Octavio Paz. Las palabras en libertad. México: Taurus, COLMEX.

Ollé-Laprune P. \& Bradu, F. (coords.) (2014). Una patria sin pasaporte. Octavio Paz y Francia. México: FCE.

PaZ, O. (2011). Por las sendas de la memoria. Prólogos a una obra. México: FCE.

PAZ, O. (2000). Miscelánea II. Obras completas. Tomo 14. México: FCE. 
PAZ, O. (2003). Miscelánea III. Entrevistas. Obras completas. Tomo 15. México: FCE.

PaZ, O. (2001). Sueños en Libertad. Escritos políticos. México: Seix Barral.

PAZ, O. (1995). Ideas y costumbres I. La letra y el cetro. Obras completas. Tomo 9. México: FCE.

PAZ, O. (1993). Itinerario. Obras Completas, Tomo 9. México: FCE.

PAZ, O. (1979). El ogro filantrópico. México: Joaquín Mortiz.

SAnti, E. M. (2009). Luz espejeante. Octavio Paz ante la crítica. México: Era, UnAm.

Sortman, G. (1992). Los verdaderos pensadores de nuestro tiempo. México: Seix Barral.

Villoro, J. \& Stavans, I. (2014). El ojo en la nuca. Madrid: Anagrama.

Toledo A. \& Jiménez Trejo, P. (1994). Creación y poder. Nueve retratos intelectuales. México: Joaquín Mortiz. 